\title{
Perceptions and Practices Regarding Sexual Activities among Girl Students
}

Sushil Sharma*

\begin{abstract}
This study attempts to reflect the perception of higher secondary level girl students towards various sexual activities. Since it is the peak point of sexual desire, they are more probable to involve in various sexual activities. The study is based on primary data, mainly focuses to dig-out the perception and practices of various sexual activities among higher secondary level girls students in Pokhara. There are 61 public and 47 private higher secondary schools in Kaski district. Out of them, 17 public higher secondary schools have education stream which is the universe population of the study. In selecting these schools as the source of study population, purposive sampling method is used. Here, eight public higher secondary schools are selected by simple random sampling method and 12 unmarried girl students are selected from each school on random basis. Altogether 96 students are considered as the respondents for the study and the questionnaire method is chosen as the tool to track-out their sexual activities. As per their responses, masturbation, premarital sex etc are found as the sexual practices. Masturbation is found to be more common in girls. In most cases, masturbation, mutual sharing of sexual knowledge and teasing and poking related to sex, observatory practice of porn films and habit of reading sex related literatures are found more common in them. In addition, parents' educational background and occupations have a lot to do with their view towards various sexual activities.
\end{abstract}

Keywords: dating, masturbation, perception, sexual desire, unusual sex

\section{Introduction}

Sexual practices refer to the manner of expression and involvement in sexual activities of human beings. Time and again people engage themselves in a variety of sexual activities for variety of reasons. Normally, people indulge themselves in sexual activities with aroused emotion together with psychological change in them. The objective of sexual activity in human beings is to achieve sexual pleasure. Here, sexual activities include those activities which are intended to arouse the sexual interest of another person. That is to say strategies of attracting the partner and calling forth for the sexual interactions.

Among the sexual activities, masturbation is more common in youth which is defined as the deliberate self-stimulation which effects sexual arousal (Shrestha, 2008). Masturbation has been often extended to encompass all activities such as rubbing, scratching, pressing or stroking of the breasts, thighs, legs, or other parts of the body including even the nose and ears, thumb

* Lecturer, P N Campus, Pokhara sucking, the biting of one's fingernails, the chewing of gum, bed wetting, fast automobile driving, high diving and still other activities that bring satisfaction to the person (Kilander, 1971). It should be recognized that the frequency of masturbation in females of most mammal species is lesser than that of males. Perhaps the interest for masturbation in males is much less than in females.

All the sexual activities conducted against the natural and social phenomena are called unusual sexual practices. Unusual sexual practices include intercourse before getting maturation, sexual harassment, homosexuality, animal sex, group sex, use of artificial devices, using clothes, tendency of watching porn films, sexual abuses, chatting and teasing with vulgar content, petting, day dreaming, etc (Khanal, 1999). During adolescent period, everyone needs proper guidance or knowledge regarding sudden changes in the body. Otherwise, they are prone to sexual abuses and unsafe sexual practices resulting to HIV/AIDS, STIs and other social and mental health problems (Kafle, 2006). As the consequences of these acts, the 
teenagers may expose to reproductive health hazards such as premature pregnancy, unwanted pregnancy, abortion and so on. Unusual sexual practices are mostly found in higher secondary level students. This malpractice has a lot to do in their future career. However, the intensity of the effects depend on the proper management and the way of dealing such practices such as social treatment to their problems, addressing religious constraints that outcasts them from community, and supportive attitude of their parents to their reproductive health.

Since, pokhara is itself a popular destination for youths for dating purpose, adolescents are found with rampant indulgence in such activities. They are usually found with such unusual sexual practices in such emotive places. Couples are found hugging, kissing, using rough words, teasing and ragging, unwanted physical contact, and also watching sex clips in mobile.

Frequent indulgences in such activities have direct impact to their career. If it is not addressed in time it may result to mental and physical problems, public harassment, blackmailing etc which may further lead to suicide and other long term effects. Furthermore, researches have also supported to the logic that one of the major causes of the students drop out is their unusual sexual activities. Therefore, to put light forth on the perception and practices concerning various sexual activities is today's urgent need.

The objectives of this study are:

i. to identify the perception towards sexual activities in girl students,

ii. to put light over the nature of sexual activities in girl students.

\section{Methods}

This study is mainly based on quantitative data as well as descriptive type of survey method. The population of the study consists of XII grade girl students of education stream of higher secondary schools of Pokhara metropolitan city. There are 108 higher secondary schools in Kaski district, among them 61 public and 47 private, out of them 17 public higher secondary schools have education stream in Pokhara metropolitan city which is considered as the universe population in this study. Here universe population is selected on the basis of purposive sampling method. Among them, eight public higher secondary schools are selected by random sampling method. Among 215 girl students from selected schools, almost 50 percent respondents are selected by the researcher. Similarly, 12 girl students are selected from each school on the basis of quota sampling using lottery method as per purposive sampling. Likewise, 96 students are considered as the sample size of the study. The researcher used the closed type of questionnaire as a research tool. Tools were revised after pretest among eight students from the same school from class XI students and after experts suggestion. In order to reduce the errors, collected data is checked and revised manually time and again, and tabulated in master table. The data is studied and evaluated using some common statistical methods with the aim to provide a broad overview on the inter relationship between different causes and effects.

The researcher paid high attention to respondent's rights to privacy and avoid unfair and illegal disclosure of confidential information. Consent of authorized person or guardian is taken to involve minors in this study. Finally, possible negative consequences to the respondents in course of study should be taken into account.

\section{Result and Discussion}

Higher secondary school students are most relevant and potential age group who are going to be exposed to reproductive life after a few years. At this stage of life, adolescents are more 
responsive towards sex and sexual activities. Physical and biological changes in body increase their sexual desires. In one hand, they are sexually active but in other, they are not aware of the reality of life and consequences of risky sexual practices.

\section{Unusual sexual practice}

Sexual practice, against natural and social phenomena is considered as unusual sexual practice. The result of the unusual sexual practice on the basis of their mothers' occupation is presented in table 1 .

Table 1. Unusual sexual practice on the basis of their mothers' occupation

\begin{tabular}{|c|c|c|c|c|c|c|c|}
\hline \multirow[b]{2}{*}{$\begin{array}{l}\text { Mother's } \\
\text { Occupation }\end{array}$} & \multirow[b]{2}{*}{ Masturbation } & \multicolumn{5}{|c|}{ Unusual sexual practice of respondents } & \multirow[b]{2}{*}{ Total } \\
\hline & & $\begin{array}{c}\text { Talking } \\
\text { about } \\
\text { Sex }\end{array}$ & $\begin{array}{c}\text { Sexual } \\
\text { Harassment } \\
\text { and } \\
\text { Exploitation }\end{array}$ & Love & $\begin{array}{l}\text { Watching } \\
\text { Glamorous Movies, } \\
\text { Reading Magazines } \\
\text { and Journals related } \\
\text { to Sex }\end{array}$ & $\begin{array}{l}\text { Premarital } \\
\text { and } \\
\text { Extramarital } \\
\text { Sex }\end{array}$ & \\
\hline Labor & $0(.0 \%)$ & $1(20.0 \%$ & $2(40.0 \%)$ & $0(.0 \%)$ & $0(.0 \%)$ & $2(40.0 \%)$ & $5(100.0 \%)$ \\
\hline Farming & $9(17.3 \%)$ & $3(5.8 \%)$ & $11(21.2 \%)$ & $3(5.8 \%)$ & $1(1.9 \%$ & $25(48.1 \%)$ & $52(100.0 \%)$ \\
\hline Business & $5(20.8 \%)$ & $2(8.3 \%)$ & $3(12.5 \%)$ & $2(8.3 \%)$ & $2(8.3 \%)$ & $10(41.7 \%)$ & $24(100.0 \%)$ \\
\hline Others & $1(6.7 \%)$ & $2(13.3 \%)$ & $4(26.7 \%)$ & $0(.0 \%)$ & $0(.0 \%)$ & $8(53.3 \%)$ & $15(100.0 \%)$ \\
\hline Total & $15(15.6 \%)$ & $8(8.3 \%)$ & $20(20.8 \%)$ & $5(5.2 \%)$ & $3(3.1 \%)$ & $45(46.9 \%)$ & $96(100.0 \%)$ \\
\hline
\end{tabular}

Table 1. demonstrates the unusual sexual behavior on the basis of their mothers' occupation. Among them, 5 are labors, 24 are businessman, 52 are farmers and 15 are in other occupations. Among those respondents whose mothers are labors, 2 responded that premarital and extramarital sex is unusual sexual practice; 2 expressed sexual harassment and exploitation is unusual sexual behavior and only one responded talking about sex is unusual sexual behavior out of 5 . Likewise, 25 responded premarital and extramarital; 11 expressed sexual harassment and exploitation, 9 responded masturbation, 3 responded talked about sex, 3 responded love and only one responded watching porn movies, reading magazines and journals related to sexual behavior out of 52 . It is quite good whose mothers are farmers. Similarly, 10 responded premarital and extramarital, 3 responded sexual harassment and exploitation, 5 responded masturbation, 2 responded talked about sex, 2 responded love and only 2 responded watching glamorous movies, reading magazines and journals related to sex out of 24. It is also good whose mothers were businesspersons and 8 responded premarital and extramarital, 4 expressed sexual harassment and exploitation, only one responded masturbation, 2 responded talked about sex, no one responded love and watching glamorous movies, reading magazines and journals related to sex out of eight respondents. Respondents' unusual sexual practices depend upon mother's occupations. Those mothers who engage in farming ultimately found their children dropped in unusual sexual practices because they are neglected from their mothers because of their busy schedule.

\section{Attraction to read and watch magazine, books, journals or movies related to sex.}

Sex is biological need, no one live without it. Each person is attracted by sexuality but different people have different techniques to quench their passion and desire. Specially, there are some causes of desireness to related sexual activities. 
Table 2. Cause of desire to read and watch magazine, books, journals or movies related to sexual activities on the basis of father's education.

\begin{tabular}{llllll}
\hline \multirow{2}{*}{ Father's Education } & \multicolumn{5}{c}{ Cause of Attraction } \\
& Sex satisfaction & Sex curiosity & Recreation & Others & \multirow{2}{*}{ Total } \\
\hline Illiterate & $2(18.2 \%)$ & $6(54.5 \%)$ & $3(27.3 \%)$ & $0(.0 \%)$ & $11(100.0 \%)$ \\
Under SLC & $5(13.2 \%)$ & $23(60.5 \%)$ & $10(26.3 \%)$ & $0(.0 \%)$ & $38(100.0 \%)$ \\
SLC & $1(6.7 \%)$ & $5(33.3 \%)$ & $9(60.0 \%)$ & $0(.0 \%)$ & $15(100.0 \%)$ \\
Intermediate & $0(.0 \%)$ & $2(40.0 \%)$ & $2(40.0 \%)$ & $1(20.0 \%)$ & $5(100.0 \%)$ \\
Bachelor/Masters & $0(.0 \%)$ & $1(33.3 \%)$ & $2(66.7 \%)$ & $0(.0 \%)$ & $3(100.0 \%)$ \\
Total & $8(11.1 \%)$ & $37(51.4 \%)$ & $26(36.1 \%)$ & $1(1.4 \%)$ & $72(100.0 \%)$ \\
\hline
\end{tabular}

Table 2 demonstrates that, out of 96 respondents, only 72 agreed upon the desire to read and watch magazine, books, journals or movies related to sex but they have quite different causes of attraction, 37 respondents replied the cause of attraction was sex curiosity. Likewise, 26 respondents replied the cause of attraction was recreation; 8 respondents said that the cause of attraction was just to fulfill sex satisfaction and only one respondent agreed for other reasons. Research shows that children are influenced by their fathers' education. Those fathers who has no education their children are attracted to read and watch magazine, books, journals or movies related to sex. So father's education is most important to reduce risky sexual practices.

\section{Perception and practice about masturbation}

Masturbation is the stimulation of the sexual organs usually by a person herself, to obtain an orgasm. Though, masturbation can be done by partners to one another, the term is more commonly used when sexual satisfaction is provided by own self. Most people use their hands to masturbate, but instruments like vibrators and other objects may also be used. Most people start masturbating at the time of puberty. Masturbation means 'sexually stimulating oneself, or someone else, usually using hands or fingers' (Carroll, 2008). This study intended to find out the relationship between perception and practice of masturbation.

Table 3. Masturbation practiced on the basis of perception

\begin{tabular}{|c|c|c|c|c|c|}
\hline $\begin{array}{c}\text { Frequency of } \\
\text { Masturbation } \\
\text { practiced }\end{array}$ & It is harmful & $\begin{array}{l}\text { Perception ab } \\
\text { IIt doesn't have } \\
\text { any negative } \\
\text { effect }\end{array}$ & At Masturbation & Don’t Know & Total \\
\hline Twice a Day & $1(11.1 \%)$ & $8(88.9 \%)$ & $0(.0 \%)$ & $0(.0 \%)$ & $9(100.0 \%)$ \\
\hline Daily & $1(12.5 \%)$ & $2(25.0 \%)$ & $1(12.5 \%)$ & $4(50.0 \%)$ & $8(100.0 \%)$ \\
\hline Weekly & $4(25.0 \%)$ & $3(18.8 \%)$ & $4(25.0 \%)$ & $5(31.2 \%)$ & $16(100.0 \%)$ \\
\hline Fortnight & $1(9.1 \%)$ & $7(63.6 \%)$ & $2(18.2 \%)$ & $1(9.1 \%)$ & $11(100.0 \%)$ \\
\hline Monthly & $13(27.7 \%)$ & $6(12.8 \%)$ & $2(4.3 \%)$ & $26(55.3 \%)$ & $47(100.0 \%)$ \\
\hline Sometimes & $0(.0 \%)$ & $2(66.7 \%)$ & $0(.0 \%)$ & $1(33.3 \%)$ & $3(100.0 \%)$ \\
\hline Total & $20(21.3 \%)$ & $28(29.8 \%)$ & $9(9.6 \%)$ & $37(39.4 \%)$ & $94(100.0 \%)$ \\
\hline
\end{tabular}

(C) 2018 HEAN 
Table 3 revels that, 94 respondents agreed about masturbation. Among those respondents who had masturbation twice a day is only one who told it is harmful, whereas, 8 told it didn't have any effect out of 9 respondents. Those respondents who practical it daily, out of 8 respondents only one told it is harmful, 2 respondents told it didn't have any negative effect, only one told it made weak and 4 told they didn't know any feelings. Likewise, out of 16 respondents who masturbated weekly, 4 respondents replied it was harmful, 3 replied it didn't have any negative effect, 4 replied it made them weak, 5 respondents replied they didn't know. Similarly who masturbated fortnight, only one told it was harmful, 7 said it didn't have any negative effect, 2 said it made them weak and only one responded she/he didn't know. As well as 47 respondents masturbate monthly. Among them, 13 agreed it was harmful, 6 agreed it didn't have any negative effect, 2 responded it made them weak and 26 respondents responded they didn't know and 3 respondents masturbated sometimes. Among them 2 agreed it didn't have any negative effect and only one agreed she didn't know it. In this study they didn't know means they did not feel any impression. Study shows that it is extremely common in young people and the reason is; it is very enjoyable and it does not do any harm.

\section{Activities for fulfilling sexual desire}

Adolescents are an age with high desire for sex. They apply various usual and risky techniques to fulfill their sexual desires. Therefore, in order to find out their usual and risky sexual practices, respondents are asked which methods they apply to fulfill their sexual desire.

Table 4. Activities to fulfill sexual desire

\begin{tabular}{llcc}
\hline S.N & Fulfill sexual desire & Frequency & Percent \\
\hline 1. & By masturbation & 13 & 13.5 \\
2. & By sexual intercourse with friends & 1 & 1.0 \\
3. & By talking about sex with friends & 37 & 38.5 \\
4. & By watching blue film & 14 & 14.6 \\
5. & By reading sex-related magazines & 15 & 15.6 \\
6. & By touching boys & 2 & 2.1 \\
7. & Others & 2 & 2.1 \\
8. & Nothing & 12 & 12.5 \\
& Total & 96 & 100.0 \\
\hline
\end{tabular}

Table 4. demonstrates that 37 respondents agreed to fulfill their sexual desire by talking about sex with friends; 15 respondents fulfill their sexual desire by reading sex related magazines; 14 respondents agree to fulfill their desire by watching porn film; 13 respondents fulfill their desire by masturbation; 12 respondents applies nothing to fulfill their sexual desire; 2 respondents says that they fulfill their sexual desire by touching boys; again 2 respond other way and only one respondent agreed with the idea of sexual intercourse with friend. So the research reveals that most of the girls focus only talking about sex with their friends for fulfillment of their desire. Similarly, 57 agreed upon talking about sex with their friends. And 39 respondents do not talk about sex.

Adolescents are more curios regarding sexual intercourse. Due to the lack of information and misleaded by seniors and peer groups, they may fall in sexual intercourse. Half of 
the school students have ever had intercourse and even once they started having sex, most teens have sex frequently. A good sex life is one that keeps in balance with everything likewise health, values, education and career goals, relationships with other people, and feelings (Masters \& Johnson, 1970). In this regard respondents are asked about the sexual relation. It is intended to find out the probability of having sexual relation during and after the dating.

\section{Conclusion}

Sex is the character which represents the gender so it is known as biological introduction. Girl students have knowledge about sex as well as there are no remarkable relations between parents' education and their professions. Respondents have good knowledge about unusual sexual practices. Respondents are interested about sex so they read and watch sex related documents as possible. Magazines, books, journals, or movies related to sex are more used by girl students. Many girls practice masturbation for sexual satisfaction. However, there individual differences revealed regarding theirperceptionaboutitsimpression. Nowadays, most girls worry of not having boyfriends. Dating is more common in younger girls. They want to meet each other in separate places. Girls have willingness of sexual relation, but there is no necessity of boyfriends and dating. Girl focuses only talking about sex with their friends for fulfillment their desires. Thus, the study demonstrates that girls who self report engaging in sexually aggressive practice are significantly more likely to misperceive sexual intent than others and cognitive knowledge contribute to sexualize interpretation of theirs behaviours.

\section{REFERENCES}

Carroll, J. L. (2008). Sexuality now: embracing diversity. ( $3^{\text {rd }}$ edition). Belmont: Wadsworth.

Kafle, R. (2006). Collected materials for reproductive health. Kirtipur: Jupitor Publication.

Khanal, K. (1999). Adolescents reproductive health in Nepal. A Journal of Reproductive Health, Vol. 3, pp. 45-53.

Kilander, H. F. (1971). Sex education in the schools. London: The Macmillan Company.

Masters, W. H., \& Johnson, V. E. (1970). Human sexual inadequacy. Boston: Little, Brown.

Shrestha, D.R. (2008). Reproductive health, national and international perspective. Dhulikhel Kavre: Ms Narayani devi shrestha. 